\title{
Engineering Identity across the Mechanical Engineering Major
}

\section{Dr. Kathleen E. Cook, Seattle University}

Kathleen Cook, Ph.D. is an Associate Professor in and Chair of the Psychology Department at Seattle University. Dr. Cook received her doctorate in Social and Personality Psychology from the University of Washington, with a minor in quantitative methods and emphases in cognitive and educational psychology. Her research has included classroom learning, person perception, identity, and health perceptions.

\section{Dr. Yen-Lin Han, Seattle University}

Yen-Lin Han is an Assistant Professor in the department of Mechanical Engineering at Seattle University. Her research interests include micro-scale molecular gas dynamics, micro fluidics, and heat transfer applications in MEMS and medical devices as well as autonomous vehicles and robotics. She is passionate about Engineering Education and experienced in developing inverted classroom lectures and facilitating students' learning through authentic engineering problems. She is currently the Co- PI for the NSF Revolutionizing Engineering and Computer Science Departments grant awarded to the Mechanical Engineering department at Seattle University to study how the department culture changes can foster students' engineering identity. Dr. Han received her BS degree in Material Science and Engineering from National Tsing-Hua University in Hsinchu, Taiwan, her PhD degree in Aerospace and Mechanical Engineering and MS degree in Electrical Engineering from the University of Southern California. She is a member of American Society of Engineering Education, American Society of Mechanical Engineering and American Educational Research Association.

\section{Dr. Gregory Mason P.E., Seattle University}

Gregory S. Mason was born and raised in Spokane Washington. He received the B.S.M.E. degree from Gonzaga University in 1983, the M.S.M.E. degree in manufacturing automation from Georgia Institute of Technology in 1984 and the Ph.D. degree in mechanical engineering, specializing in multi-rate digital controls, from the University of Washington in 1992. He worked in a robotics lab for the Department of Defense for five years after receiving his M.S.M.E. He is currently a Professor in the Department of Mechanical Engineering at Seattle University, Seattle, WA. His research interests are controls system and the use of technology to enhance engineering education. Dr. Mason is a member of the American Society of Engineering Education and the Society of Manufacturing Engineers. He is a licensed professional engineer.

\section{Dr. Teodora Rutar Shuman, Seattle University}

Professor Teodora Rutar Shuman is the Chair of the Mechanical Engineering Department at Seattle University and an Affiliate Professor at the University of Washington. She is the PI on a NSF-RED grant "Revolutionizing a Mechanical Engineering Department through Industry Immersion and a Focus on Identity". Her research also includes NOx formation in lean-premixed combustion and electro-mechanical systems for sustainable processing of microalgae. Her work is published in venues including the Journal of Engineering Education, IEEE Transactions on Education, ASME Journal of Mechanical Design, Bioresource Technology, Chemical Engineering Journal, Proceedings of the Combustion Institute, and Combustion and Flame. She is a member of the American Society of Engineering Education, American Society of Mechanical Engineers, and the Algae Biomass Organization. Dr. Shuman recently served as Chair for the ASEE Energy Conversion and Conservation Division.

She received a Dipl.Ing. degree in mechanical engineering from Belgrade University in 1992, an M.S.M.E. from the University of Washington in 1994 and a Ph.D. from the University of Washington in 2000.

\section{Dr. Jennifer A. Turns, University of Washington}

Jennifer Turns is a Professor in the Department of Human Centered Design \& Engineering at the University of Washington. She is interested in all aspects of engineering education, including how to support 
engineering students in reflecting on experience, how to help engineering educators make effective teaching decisions, and the application of ideas from complexity science to the challenges of engineering education. 


\title{
Implicit Engineering Identity in the Mechanical Engineering Major
}

\begin{abstract}
The Mechanical Engineering Department at Seattle University was awarded a National Science Foundation RED (Revolutionizing Engineering and Computer Science Departments) grant in 2017 to study how student identities are affected when a department makes "revolutionizing" changes. These can result in graduates who not only are prepared technically and professionally with a practical, realistic understanding of what it is to be an engineer, but also who identify with and are committed to the engineering profession. The expectation is that immersion in this program will affect students' identities as they move through the program. This paper focuses on implicit identity data collected via implicit association tests (IATs) during the first year of the five-year grant. It shows that although engineering students in the current program implicitly identify with engineering, both men and women consider engineering to be a male field. These data serve as a baseline for the ongoing identity research supported by the grant and point to the need for programmatic changes that help females and non-Whites develop stronger identities with engineering.
\end{abstract}

\section{Introduction}

In 2017, the Mechanical Engineering Department at Seattle University was awarded a National Science Foundation grant to revolutionize the department. The department's proposal centers on creating a program where students develop strong identities as engineers. It leverages the department's small size and close ties with industry to create a culture of "Engineering with Engineers." Details of the program changes in progress can be viewed as part of the 2018 and 2019 ASEE NSF Grantees' poster sessions and papers [1], [2]. The background section of this paper draws on a work-in-progress poster presented at the 2018 ASEE Annual Conference that reported on students' explicit engineering identities as measured by the ESIS-2 [3].

\section{Background: Why Identity Matters}

Identity influences who people think they are, what they think they can do and be, and where and with whom they think they belong [4]- [16]. In academic contexts, identity influences whether people feel they belong in a program and what they believe they can achieve; it affects goals they pursue, and the level and type of effort put towards those goals [14]. When people perceive a fit between themselves and their environments, they persist longer in those environments [17]- [19]. In engineering, identity is an important factor in people pursuing, persisting, and persevering [16], [20]. Brainard and Carlin's [21] longitudinal study found that freshmen students' identities were better predictors of long-term persistence than even GPAs or self-efficacy.

Lee [15] showed that identity is an especially important factor affecting whether women remain in STEM fields. Park, Cook, and Greenwald's [22] study using implicit measures revealed that identification with STEM may be one of the key factors influencing decisions to persist in STEM 
fields. Although women's attitudes toward engineering are positive, women perceive engineering as a male field [22], [23]. When their gender roles and their behaviors (e.g., occupations) don't match, women may experience identity conflict [24]. This gender role conflict may affect women's disproportionate attrition from STEM fields [22].

Although identity theory has been heavily researched in psychology [4]- [15], [18], [19], [25], it has not been a focus in engineering [16], [20]. Few studies investigate how developing an engineering identity would improve retention of engineering students, especially of women and underrepresented minorities. Recognizing that engineering identity is understudied, and that it could be a factor contributing to engineering gender and ethnicity gaps, the National Science Foundation awarded Seattle University a grant to study how to build a culture that fosters students' engineering identities and how such engineering identities could affect the persistence and perseverance of students in engineering fields.

Because identity influences people's belonging, goals, efforts, commitment, and perseverance, and because identity may play a role in retaining engineering students, it is important to understand students' identities. Understanding students' current identities is critical to evaluating the impact of future program changes, and to elucidating where changes might be most effective.

\section{Measuring Identity: Explicit Measures}

Explicit, direct measures, such as self-reports and questionnaires, tap into people's controlled, deliberate, and conscious cognitive processes [26], [27]. They ask respondents to report their answers to statements or questions, often via Likert scales. While a ubiquitous method, there are reasons to be concerned about self-reported data. People are often unable or unwilling to report their true attitudes, beliefs, or identities [28]. To share one's psychological characteristics, one must be aware of and able to access one's feelings, cognition, and behavior, and one must be comfortable sharing that information, however anonymized. Moreover, even when people sincerely share, there is reason to be concerned about veracity of the information reported; for example, strong agreement with the statement, "I treat all others equally," may represent what people think or wish were true, but not what their behavior actually is. To address these concerns, psychology has turned increasingly to implicit measures to assess individuals' characteristics.

\section{Measuring Identity: Implicit Measures}

Implicit measures tap people's uncontrolled, nonconscious, and automatic responses to stimuli [26]. Implicit measures access thoughts and feelings not available to conscious introspection and self-report [29]. The benefit of using implicit measures is that they can circumvent problems like social desirability biases, self-presentational concerns, or people's inability to access internal processes [22]. There are numerous tools for assessing implicit or unconscious qualities (see [28] for a review). One of the most extensively used and thoroughly studied is the Implicit Association Test or IAT [30]. The IAT measures the relative ease with which people make automatic associations between target concepts and attributes. Strongly associated conceptattribute pairs (such as flower and pleasant) should be easier to categorize together than weakly associated concept-attribute pairs (such as insect and pleasant). 
The IAT is a computerized task. Participants are presented with a series of words (or pictures) on a screen, one at a time, and they must categorize each word as quickly as possible. The ease of classifying a concept with an attribute is measured by the response times and errors in the categorizations. The automatic association is determined by taking the difference in response latency times and errors between the two opposing configurations, for example, between when insect and unpleasant are mapped together and when insect and pleasant are mapped together.

The literature on the IAT is extensive; "Implicit Association Test" generates 2,310,000 hits in google scholar (Feb. 2, 2019). The reliability, validity, and utility of the IAT have been established repeatedly [31]- [33].

\section{Identity IATs}

An IAT measuring identification with engineering assesses the strength of associations between engineering terms (or arts and literature terms) and "self" (or "other") terms. Associations that are made with greater speed and fewer errors reflect stronger identification. For example, someone who finds it easier to put "self" with engineering shows a stronger identification with engineering than a person who finds it easier to put "self" with arts/literature.

The gender IAT measures the strength of associations between male (or female) and engineering (or arts and literature). For example, someone who finds it easier to put "male" with engineering than "female" with engineering identifies engineering as male.

\section{Current Project}

The goal of the current study is to assess the implicit identities of engineering students in the mechanical engineering department at Seattle University. The expectation is that enrolled students will identify with engineering, and will consider engineering to be masculine. Demographic differences are also assessed.

\section{Method}

All undergraduates enrolled in the mechanical engineering program at a private, mid-sized university $(N=117)$ were invited to participate in two implicit association tests (IAT's [30]). The program utilizes a cohort model where all students at each level (freshmen, etc.) take at least one of the major's courses together. One of the authors not teaching any of these courses visited each cohort's classroom and invited students to access the IATs delivered by IATGEN [35] and Qualtrics via their phones. After consenting, students completed several demographic questions (age, year in school, whether a transfer student, and perceived gender and ethnicity) and then two IAT's, one measuring their association or identity with engineering and one assessing their association of gender with engineering. Each participant completed one of four randomly assigned counterbalanced IAT orders. All participants, whether or not they completed the task, were given $\$ 3.00$ for participation. 
Of the 117 possible participants, 97 completed both IATs and 3 more completed one of them, for a total participation $N$ of 100 .

\section{The IATs}

Both the Engineering Identity and Gender IATs used engineering and arts/literature terms. These terms were drawn from pretested math, science, and engineering stimuli used in prior research [22]. Additional, engineering-specific terms were pretested by a small group of mechanical engineers; those terms that all rated as strongly representative were included. Self and other terms as well as gender terms were also drawn from prior research [22], [34]. The terms used in both IATs are provided in Table 1.

Table 1. IAT stimuli.

\begin{tabular}{|l|l|}
\hline Engineering & $\begin{array}{l}\text { MATH, ANALYSIS, SCIENCE, ENGINEERING, CAD, } \\
\text { MATHEMATICIAN, SCIENTIST, MACHINE, ENGINEER, INDUSTRY, } \\
\text { CALCULUS, CARS, MECHANICAL, ELECTRICAL, COMPUTER }\end{array}$ \\
\hline Arts/Literature & $\begin{array}{l}\text { ART, ARTIST, MUSIC, DRAMA, DANCE, SING, ACTOR, PAINT, } \\
\text { SCULPTOR, DICTIONARY, ENGLISH, WRITER, POET, GRAMMAR, } \\
\text { JOURNALIST }\end{array}$ \\
\hline Self & SELF, I, ME, MY, MINE \\
\hline Other & OTHER, THEY, THEM, THEIR, IT \\
\hline Male & MALE, MAN, HIM, HIS, HE \\
\hline Female & FEMALE, WOMAN, HER, HERS, SHE \\
\hline
\end{tabular}

\section{IAT Scoring and Analysis}

The raw IAT data were analyzed via the Shiny application provided by the developers of the IAT for Qualtrics (IATGEN) [35]. The app cleans, provides key diagnostics (e.g., error rate), and derives $D$ scores as described by Greenwald and colleagues [36]. $D$ scores are the effect represented as the mean difference between two groups in standard deviation units based on both conditions, while accounting for error rates. Participants' $D$ scores were compared using SPSS [37].

In terms of the engineering identity IAT, a larger, positive $D$ means that the difference between the first (in this case engineering + other) and second pair (engineering + self) is larger, or specifically, that a participant was much slower to put engineering with other than with self. In terms of the gender IAT, a larger negative $D$ means that the difference between the first (in this case engineering + male) and second pair (engineering + female) is larger, or specifically, that a participant was much slower to put mechanical engineering with female than mechanical engineering with male.

\section{Results}

Engineering Identity IAT. Participants have an average $D$ of $.305(S D=.348)$, indicating that there is a significant difference between the speed of categorization of engineering with others and engineering with self, $t(98)=8.74, p<.001$. Men $(N=74)$ have a mean $D$ of $.322(S D=$ 
$.352)$ whereas women's $(N=25)$ is $.258(S D=.336)$. Although women were slower than men to categorize engineering with the self, the difference is not significant, $t(97)=.793, p=.430$.

Similarly, participants identifying as non-White $(N=46, D=.268, S D=.353)$ were slower than Whites $(N=53, D=.338, S D=.344)$ to categorize engineering with the self; the difference also is not significant, $t(97)=.998, p=.321$.

Combining gender and ethnicity does not produce a significant interaction, $F(1,95)=1.203, p=$ .276 (see Figure 1). White men have the strongest effect with a mean $D$ of $.369(S E=.054)$; nonWhite men have a mean $D .259(S E=.062)$. Non-White women have a mean $D$ of $.288(S E=$ .093 and White women have the lowest mean $D$ of $.219(S E=.105)$.

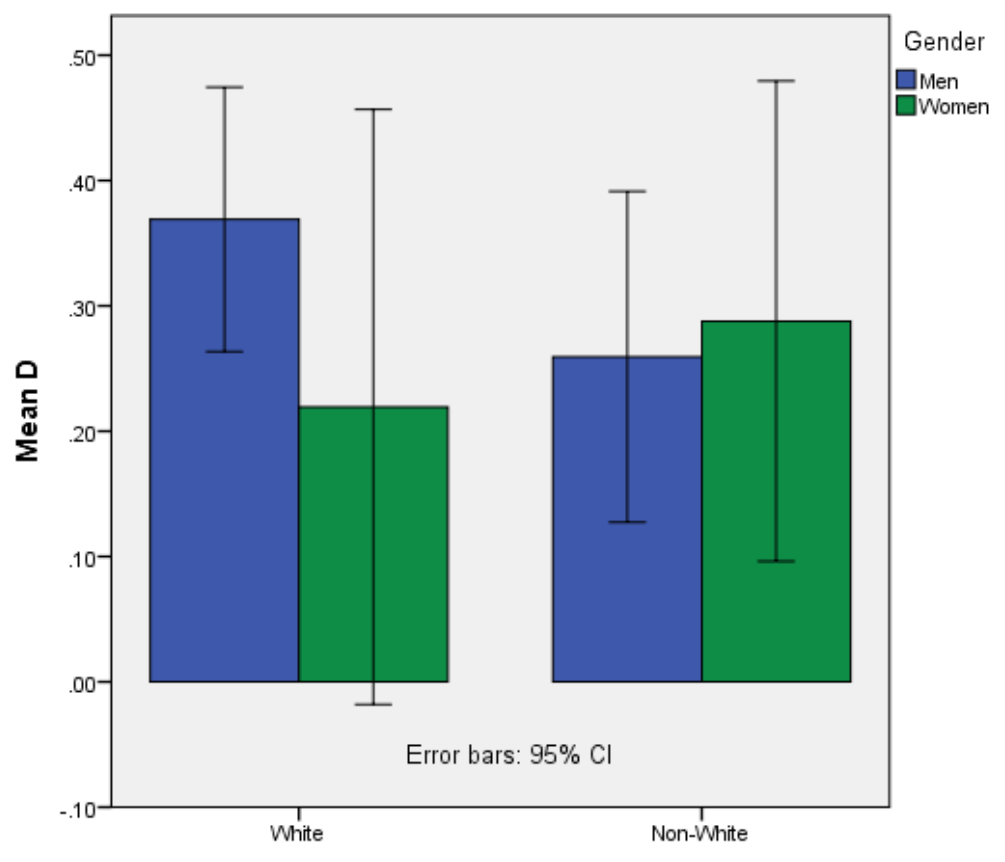

Figure 1. Comparison of responses for White and non-White groupings. Larger positive mean indicates stronger association of Self with Engineering.

Gender IAT. Participants have an average $D$ of $-0.376(S D=.378)$, indicating that there is a significant difference between the speed of categorization of engineering with male and engineering with female, $t(99)=-9.95, p<.001$. As a whole, participants associate engineering with male. Men $(N=75)$ have a mean $D$ of $-.449(S D .=358)$, whereas women's $(N=25)$ is -.157 $(S D=.358)$. The difference is significant, $t(98)=-3.541, p=.001$. Although both genders associate engineering more easily with male than female, men do so significantly faster than women do.

Whites $(N=55, D=-.436, S D=.345)$ were faster than non-Whites $(N=45, D=-303, S D=$ .407 ) to categorize engineering with males. The difference is not significant, $t(98)=-1.769, p=$ .80. Combining gender and ethnicity does not produce a significant interaction, $F(1,96)=2.142$, $p=.147$. See Figure 2 . White men $(N=44)$ most strongly associate engineering with male with a 
mean $D$ of -.466 $(S E=.352)$; non-White men $(N=31)$ have a mean $D-.425(S E=.370)$. White women $(N=11)$ have a mean $D$ of $-.315(S E=.297)$ and non-White women $(N=14)$ have the lowest mean $D$ of $-.032(S E=.361)$.

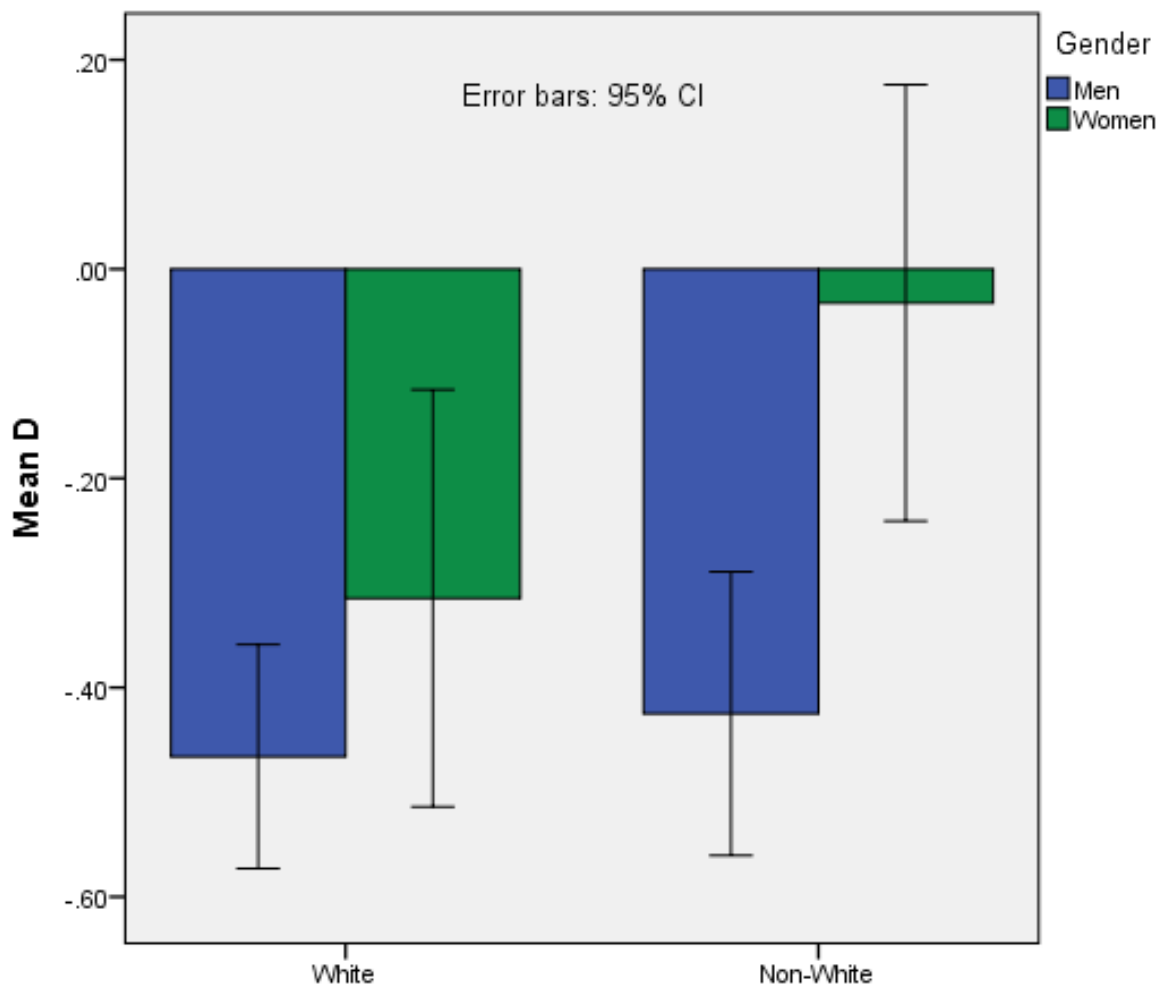

Figure 2. Comparison of responses for White and non-White groupings. Larger negative mean indicates stronger association of Male with Engineering.

\section{Discussion}

All students participating in the IAT identify with engineering. This is a positive and expected result as all participants were students enrolled in mechanical engineering. Although the association for men is stronger, the difference between men's and women's identity IAT scores was not significant.

All participating students identified engineering as a male field. This is somewhat concerning, but not unexpected. Both men and women more easily associate engineering with male than with female. Furthermore, men make these associations significantly easier than women, with men considering engineering even more male than women do. Such identification does not provide a conflict for men, but for women, their gender and their field choice are at odds. For a program to be inclusive, men and women, Whites and non-Whites, will have to see engineering as both male and female. 
The results of these baseline IATs point to the need for programmatic changes that help females and non-Whites develop stronger identities with engineering, and help all students view engineering as both male and female.

As mentioned in the introduction, the program changes in progress are reported in the 2019 ASEE NSF Grantee Poster Session and paper [2]. Specific changes that we anticipate will strengthen the engineering identities of underclassman and underrepresented minorities include vertically integrated design courses and bringing engineering professionals to campus.

The vertically integrated design courses will be required of all freshman, sophomores and juniors. They will bring together students from across the program into diverse, well-supported teams. Industry is being brought to campus through guests in seminars and courses, and through the department's new industry consultant. These opportunities allow students to connect with each other and engineering professionals which in-turn strengthens their engineering identities. In the years ahead, we hope to strengthen the engineering identities of all in the engineering program, especially those of women and underrepresented minorities.

IATs will be administrated every year to follow the impact of changes in the program. Although the participation rate is high at $83 \%$ in this study, it is plausible that those who chose not to participate differed in identification from those who did. It will be important to maximize participation in future data collection.

These IAT results serve as students' baseline engineering identities. As we revamp our mechanical engineering program, what we learn will lead to a clearer understanding of the changes that promote engineering identities, especially in women and minorities, and how such identities affect students' sense of belonging in a program and their persistence in the major.

\section{Acknowledgements}

This project was funded by the NSF IUSE/PFE: RED grant \#1730354.

\section{References}

[1] Y.-L. Han, K. E. Cook, G. Mason, T. R. Shuman, and J. Turns, "Engineering with Engineers: Revolutionizing Engineering Education through Industry Immersion and a Focus on Identity", Proceedings of American Society for Engineering Education Annual Conference. Salt Lake City, UT: ASEE 2018.

[2] Y.-L. Han, K. E. Cook, G. Mason, T. R. Shuman, and J. Turns, "Engineering with Engineers: Revolutionizing Engineering Education through Industry Immersion and a Focus on Identity", Proceedings of American Society for Engineering Education Annual Conference. Tampa, FL: ASEE 2019.

[3] K. E. Cook, Y.-L. Han, G. Mason, T. R. Shuman, and J. Turns, "Work-in-Progress: Engineering Identity across the Mechanical Engineering Major", Proceedings of American Society for Engineering Education Annual Conference. Salt Lake City, UT: ASEE 2018. 
[4] K. Deaux, "Reconstructing social identity," Personality and Social Psychology Bulletin, vol. 19(1), pp. 4-12, 1993.

[5] S. Stryker, and P. J. Burke, "The Past, Present, and Future of an Identity Theory," Social Psychological Quarterly, vol. 63(4), pp. 284-297, 2000.

[6] E. H. Erikson, Identity and the life cycle. New York: International Universities Press, 1959.

[7] M. B. Brewer, "The Social Self: On Being the Same and Different at the Same Time," Personality and Social Psychology Bulletin, vol. 17(5), pp. 475-482, 1991.

[8] J. E. Dutton, J. M. Dukerich, and C. V. Harquail, "Organizational Images and Member Identification," Administrative Science Quarterly, vol. 39(2), pp. 239-263, 1994.

[9] G. H. Mead, Mind, Self and Society (Vol. 111). Chicago: University of Chicago Press, 1934.

[10] S. Stryker, Symbolic Interactionism: A Social Structural Version. Benjamin/Cummings: Menlo Park, CA, 1980.

[11] R. B. Cialdini, R. J. Borden, A. Thorne, M. R. Walker, S. Freeman, L. R. Sloan, "Basking in Reflected Glory: Three (Football) Field Studies," Journal of Personality and Social Psychology, vol. 34(3), pp. 366-375, 1976.

[12] H. Tajfel, and J. C. Turner, "The social identity theory of intergroup behavior," in Psychology of Intergroup Relations, S. Worchel, \& W. G. Austin, Eds. Chicago, IL: NelsonHall, pp. 7-24, 1986.

[13] J. D. Lee, "More Than Ability: Gender and Personal Relationships Influence Science and Technology Involvement," Sociology of Education, vol. 75(4), pp. 349-37, 2002.

[14] B. R. Schlenker, "Identity and self-identification.," in The Self in Social Life, B. Schlenker, Ed. New York: McGraw-Hill, 1985.

[15] J. D. Lee, "Which Kids Can "Become" Scientists? Effects of Gender, Self-Concepts, and Perceptions of Scientists," Social Psychology Quarterly, vol. 61(3), pp. 199-219, 1998.

[16] O. Pierrakos, T. K. Beam, J. Constantz, A. Johri, and R. Anderson, "On the development of a professional identity: Engineering persisters vs. engineering switchers," Proceedings of Frontiers in Education Conference, San Antonio, TX: FIE, 2009.

[17] S. E. Cross, and N. V. Vick, "The Interdependent Self-Construal and Social Support: The Case of Persistence," Personality and Social Psychology Bulletin, vol. 27(7), pp.820-832, 2001.

[18] A. L. Kristof, "Person-Organization Fit: An Integrative Review of its Conceptualizations, Measurement, and Implications," Personnel Psychology, vol. 49(1), pp.1-49, 1996.

[19] O. Pierrakos, N. A. Curtis, and R. Anderson, "How salient is the identity of engineering students? On the use of the Engineering Student Identity Survey," Proceedings of Frontiers in Education Conference, Erie, PA, FIE: 2016.

[20] T. K. Beam, O. Pierrakos, J. Constanz, A. Johri, and R. Anderson, "Preliminary findings on freshmen engineering students' professional identity: Implications for recruitment and retention," Proceedings of American Society for Engineering Education Annual Conference. Washington, DC: ASEE, 2009. 
[21] S. G. Brainard, and L. Carlin, "A Six-Year Longitudinal Study of Undergraduate Women in Engineering and Science," Journal of Engineering Education, vol. 87(4), pp. 369-375, 1998.

[22] L. E. Park, K. E. Cook, and A. G. Greenwald, "Implicit Indicators of Women's Persistence in Math, Science, and Engineering," Psi Chi Journal of Undergraduate Research, vol. 6(4), pp. 145-152, 2001.

[23] L. S. Keller, "Discovering and doing: Science and technology: An introduction," in Inventing Women: Science, Technology and Gender, G. Kirkup and L. S. Keller, Eds. Cambridge, UK: Polity Press, pp. 122-132, 1992.

[24] H. Luhaorg, and M. T. Zivian, "Gender Role Conflict: The Interaction of Gender, Gender Role, and Occupation,” Sex Roles, vol. 33(9), pp. 607-620, 1995.

[25] R. Spears, B. Doosje, and N. Ellemers, "Self-stereotyping in the face of threats to group status and distinctiveness: The role of group identification," Personality and Social Psychology Bulletin, vol. 23, pp. 538-553, 1997.

[26] K. E., Cook, L.E., Park, and A.G., Greenwald, “Implicit associations and women's commitment to math, science and engineering". Paper presented at the annual meeting of the American Psychological Society, Miami, FL: 2000.

[27] B. A. Nosek. "Implicit-explicit relationships," Current Directions in Psychological Sciences, vol. 16, pp. 65-69, 2007.

[28] B. Gawronski, \& J. De Houwer, "Implicit Measures in Social and Personality Psychology," in Handbook of Research Methods in Social and Personality Psychology, H. T. Reis and C. M. Judd, Eds. Cambridge University Press, pp, 283-310, 2014.

[29] A. G. Greenwald, and M. R. Banaji, "Implicit social cognition: Attitudes, self-esteem, and stereotypes," Psychological Review, vol. 102(1), pp. 4-27, 1995.

[30] A. G. Greenwald, D. E. McGhee, and J. L. Schwartz, "Measuring Individual Differences in Implicit Cognition: The Implicit Association Test," Journal of Personality and Social Psychology, vol. 74(6), pp. 1464-1480, 1998.

[31] A. G. Greenwald, T. A. Poehlman, E. L. Uhlmann and M. R. Banaji, "Understanding and using the Implicit Association Test: III. Meta-analysis of predictive validity," Journal of Personality and Social Psychology, vol. 97(1), pp. 17-41, 2009.

[32] K. A. Lane, M. R. Banaji, B. A. Nosek, and A. G. Greenwald, "Understanding and Using the Implicit Association Test: IV What We Know (So Far) about the Method," in Implicit Measures of Attitudes, B. Wittenbrink and N. Schwarz, Eds. The Guilford Press, 2007.

[33] B. A. Nosek, A. G. Greenwald and M.R. Banaji, "Understanding and Using the Implicit Association Test: II. Method Variables and Construct Validity," Personality and Social Psychology Bulletin, vol. 31(2), pp. 166-180, 2005.

[34] A. G. Greenwald and S. D. Farnham, "Using the Implicit Association Test to measure selfesteem and self-concept," Journal of Personality and Social Psychology, vol. 79(6), pp. 10221038, 2000. 
[35] T. Carpenter, R. Pogacar, C. Pullig, M. Kouril, S. Aguilar, J. P. LaBouff, and A. Chakroff, "Conducting IAT Research within Online Surveys: A Procedure, Validation, and Open Source Tool," PsyArXiv. December 2018. [online]. Available: https://doi.org/10.31234/osf.io/hgy3z. [Accesses Feb. 2, 2019].

[36] A. G. Greenwald, B. A. Nosek and M. R. Banaji, "Understanding and using the Implicit Association Test: I. An Improved Scoring Algorithm," Journal of Personality and Social Psychology, vol. 85(2), pp. 197-216, 2003.

[37] IBM Corp, IBM SPSS Statistics for Windows, Version 22.0. Armonk, NY: IBM Corp, 2013. 